\title{
The burden of dental caries in the Western Cape and a recommended turn-around strategy.
}

SADJ September 2017, Vol 72 no 8 p360 - p365

DA Smit', RB Barrie ${ }^{2}$, AJ Louw ${ }^{3}$

\begin{abstract}
Oral diseases are mostly preventable and their prevention should be a top priority for health managers and oral health professionals. Oral health services data from 2011 to 2015 is compared with the National Children Oral Health Survey conducted in 1999 - 2002. Dental caries is amongst the most common diseases experienced in children. The Western Cape records the highest prevalence of dental caries among children of the ages $4-5,6,12$ and 15 years, which has increased between 2002 and 2015, for six year olds (2011: 82\% to 2015: 84\%) and for 12 year olds ( 2003: $62 \%$ to 2015: 67\%). Caries severity was measured in dmft- and DMFT-scores. Between 2003 and 2015, dmft in 6-year-olds increased by 13\%, from 5.5 to 6.2, whilst DMFT in 12 year-olds showed an increase of 0.5 (2 to 2.5). Given these persistently high levels, current prevention strategies are clearly failing. It is crucial that decision makers implement health strategies that focus on promoting good oral health and preventing oral disease. This requires a shift away from the current predominantly emergency service of dental extractions.
\end{abstract}

\section{INTRODUCTION}

The mouth plays a vital role in general well-being and contributes to the social life of the patient. ${ }^{1}$ Oral diseases, especially dental caries, can result in severe pain and discomfort and lead towards escalating health care costs. Pathological changes in the oral cavity may contribute to inadequate food intake and possibly, malnutrition. Oral diseases are, however, mostly preventable and therefore the promotion of oral health and primary prevention should be a top priority for health managers and oral health professionals.

1. DA Smit: BChD (Stellenbosch/Western Cape), MChD (CommDent) Western Cape). Department of Maxillo-Facial- and Oral Surgery, University of the Western Cape, South Africa

2. RB Barrie: BChD Hons, MChD, MPA (Stellenbosch), PhD (Western Cape), FICD. Community Oral Health, University of the Western Cape, South Africa.

3. AJ Louw: BChD (Pretoria), BScMedSciHons (Stellenbosch), $M C h D$ (Pretoria). Community Oral Health, University of the Western Cape, South Africa.

\section{Corresponding author}

\section{DA Smit:}

Tygerberg Oral Health Centre, Private Bag X1, Tygerberg, 7505, South Africa. Tel: +27 21937 3085. E-mail: dirkiesmit@gmail.com
The serious nature of early childhood caries in the Western Cape is evidenced by the high number of young children who are treated under general anaesthetic in various facilities. ${ }^{2}$ In most cases treatment is limited to multiple extractions, a treatment intervention which can have further psychological and functional consequences. Oral diseases are generally not life-threatening but contribute towards a morbidity that affects the majority of people in the country.

This article reports on a comparison of recent oral health services data (2011 - 2015) with historical epidemiological data extracted from the last National Children's Oral Health Survey which was conducted in $1999-2002 .^{3}$ It will also advocate for an integrated oral health strategy to promote primary oral health.

\section{LITERATURE REVIEW}

Dental caries is amongst the most common of the childhood diseases. ${ }^{4}$ The prevalence and severity of dental pain among children in South Africa is much higher than in England and the USA. ${ }^{5}$ Children with both poor oral health and weak general health are 2.3 times more likely to perform poorly in school. ${ }^{6}$ Dental disease in children leads to lost school time and increased absence from school had been shown to decrease academic performance. ${ }^{?}$

The Western Cape is the South African province with the highest prevalence of dental caries among children of the ages $4-5,6,12$ and 15 years while the province with the lowest prevalence is Limpopo. ${ }^{8}$ Dental caries is particularly severe in the primary dentition, where it is measured by using dmft-scores referring to the number of decayed, missing and filled teeth. The prevalence of dental caries refers to the percentage of children in a sample who have a d-component score of more than zero.

Caries experience refers to the percentage of children who have a dmf-score of more than 0.9. The last South African National Oral Health Survey conducted in the period 1999 - 2002, indicated that the caries experience of 4 - 5-year-old children in the Western Cape was $77.1 \%$ and in 6-year-olds, $82.3 \% .^{8}$ This is much higher than the national means which are 50.59\% and 60.32\% for these particular age groups. ${ }^{3}$ A factor which adds more concern to these alarming statistics is the high percentage of unmet need. Almost $80 \%$ of carious lesions in 6 year-old-children within the province are untreated. 
The consequences of untreated caries are among the most common reasons why children are hospitalized due to infectious complications. ${ }^{10,11}$ Furthermore, untreated nursing or rampant dental caries can affect a child's growth and general health and wellbeing.12-14

Poor oral health can also contribute towards loss of school days, ${ }^{7}$ and loss of productivity in the work place. In some cases children are embarrassed to smile. ${ }^{14}$ Dental caries is a silent epidemic that affects many people. It restricts activities in schools, work, and home, and often significantly diminishes their quality of life..$^{15}$

The dental treatment performed under general anesthesia is usually dental extractions. An analysis on dental general anesthetic (GA) cases on pre-school children in the Western Cape indicated that 1 in 10000 cases (0.0001\%) received restorative treatment. The average number of teeth being extracted per patient was ten. ${ }^{2}$ The alarming findings from that study are contrary to the globally suggested guidelines which advocate preserving the primary dentition. Furthermore, the probability of retreatment for dental caries after dental GA can be as high as $45.5 \% .^{16-18}$

According to national policy documents, basic oral health care must be available in public dental clinics. These documents include the National Oral Health Policy, ${ }_{19}^{19}$ National Oral Health Strategy, ${ }^{20}$ and Norms and Standards for Oral Health Care in South Africa. ${ }^{21}$ The basic oral health care package includes prevention of oral disease, mainly dental caries, promotion of oral health and lastly basic oral health care treatment which includes an oral examination, bitewing radiographs, scale \& polish, 1-3 surface fillings and extractions. ${ }^{20}$ However, only a third of clinics in the province can offer the basic oral health care package and $60 \%$ of clinics are limited to offer only dental extractions. ${ }^{22}$ The study conducted by Smit also found that less than half of the clinics (43\%) are able to offer scale and polish prophylaxis (S\&P) or fillings. Only 37\% of clinics can offer fissure sealants and bitewing radiographs can be taken at only $30 \%$ of clinics. ${ }^{22}$ The American Academy of Paediatric Dentistry (AAPD) defines early childhood caries as the occurrence of decay affecting at least one primary tooth in a child under 6 years of age. ${ }^{23}$

The estimated prevalence of early childhood caries in developed countries is between $1 \%$ and $2 \%$ while the prevalence in less developed countries is $70 \% .^{7}$ In developing countries, communities are disadvantaged and the people are from a much lower socio-economic background. The current study showed that in the permanent dentition in 12 year olds, $62 \%$ of teeth are affected while in 15 -year olds, almost $81 \%$ of the dentition is affected which is almost twice the national figure. ${ }^{8} \mathrm{~A}$ main reason for concern is that a large number of children who suffer from early childhood caries are not being treated. In many households there is a lack of education and negligence of parents combined with limited resources to provide effective care. The limited infrastructure, seen especially in the less developed areas, leads to fewer children being treated per occasion. In rural districts there are not enough oral health professionals to address appropriately the patient's main complaint. ${ }^{22}$

\section{AIM}

To investigate the burden of dental caries in the Western Cape and to compare those findings with the data reported in the last National Children's Oral Health Survey of 1999-2002.

\section{OBJECTIVES}

- To discuss the National Children's Oral Health Survey of 1999-2002

- To analyze the caries experience and severity recorded in the most recent caries surveillance data of the Department of Health in the Western Cape (2011 to 2015) among 6- and 12-year old children

- To compare the results of the Departmental survey with those of the current study.

\section{MATERIAL AND METHODS}

The first part of this article will focus on results obtained from the last National Oral Health Survey conducted in 1999-2002 by the National Department of Health ${ }^{24}$ to determine the oral health status of adults and children (6-, 12-, and 15-years of age) in the five major metropolitan areas of South Africa. ${ }^{2}$ Secondly, the paper will focus on the most recent surveillance data for dental caries in the Western Cape obtained in 2015. These data are being collected on an on-going basis to evaluate a fissure sealant roll-out for 6 year olds and 12 year olds in targeted provincial schools throughout the province. The examiners were all standardized according to the guidelines provided by the WHO Oral Health Surveys, Basic Methods methodology (4th Edition) $)^{9}$ in the understanding of the precise criteria for the identification of each caries status and treatment need code. A formal calibration exercise was not carried out, as it was not feasible to do so for all the dentists employed in the public sector throughout the province. The Department of Health is responsible for the Oral Health preventive and treatment services for schools in lower socio-economic areas. At each school a random sample of 20 six year olds and 20 twelve year olds who met the age criteria was selected from names on the class lists. If there were less than 20 children who qualified in terms of age, all the qualifying children were examined. The subjects were examined at the school, using a portable dental chair and a portable dental light, a WHO probe and a plane mirror. The caries status and treatment needs were recorded on a modified WHO Oral Health Surveys data collection form. A total of 3427 learners were examined from 194 schools and the programme is on-going. The data were analyzed using a custom software program for measuring oral health surveys and, using Microsoft Excel, the results were calculated and presented according to the WHO guidelines.

\section{National Children's Oral health Survey (NCOHS)} (1999 - 2002)

The last National Oral Health Survey which was conducted in 2002 reported that more than $82 \%$ of 6 year old children in the Western Cape have experienced dental caries and $75 \%$ of the children in this age category remained untreated. ${ }^{8}$ The Western Cape had the second highest levels of dental caries the country (Figure 1). The caries experience in the Western Cape was 22\% higher than the national mean which was $60 \%$. The province with the highest caries experience was Northern Cape with $84 \%$. Other provinces had caries experience around the $52 \%$ - 68\% levels except for Limpopo which recorded the lowest prevalence of $37 \%$. The national percentage for untreated caries was $55 \%$, which is $20 \%$ less than the figure recorded for the Western Cape. 


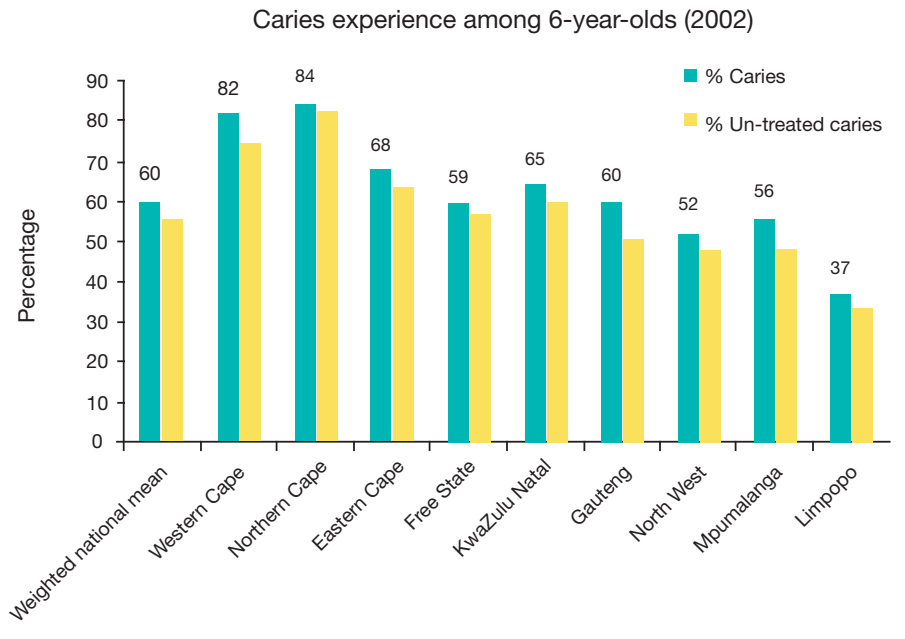

Figure 1: National Children's Oral Health Survey (NCOHS) of South Africa by Province: Caries Experience among 6 year-olds (2002)

Caries experience among 12-year-olds (2002)

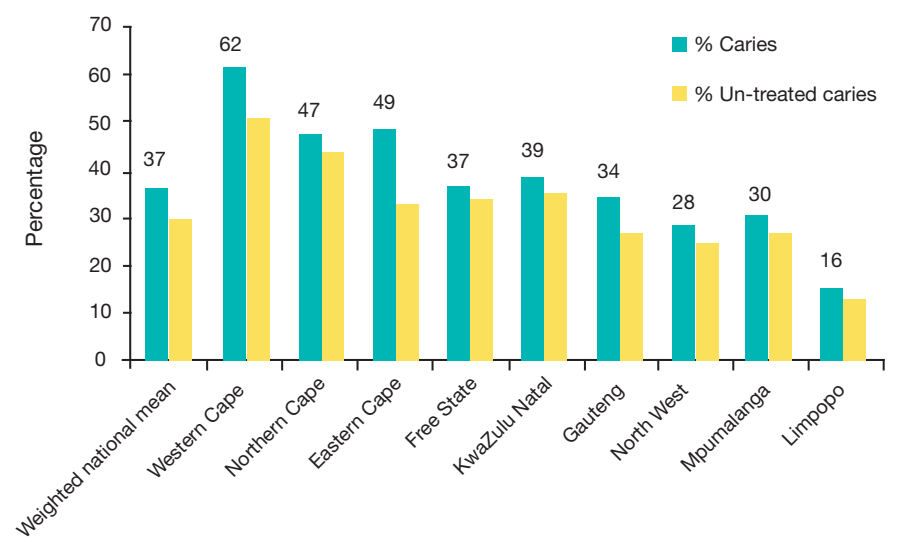

Figure 2: National Children's Oral Health Survey (NCOHS, 2002) of South Africa by Province: Caries Experience among 12 year-olds.

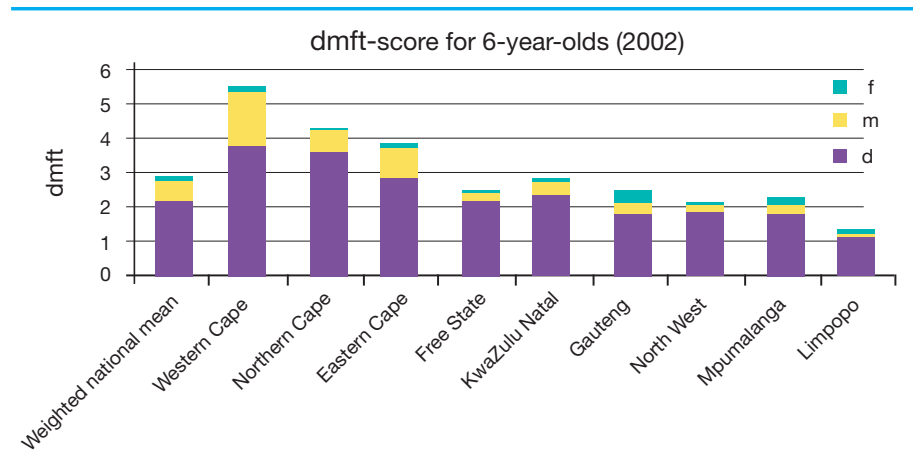

Figure 3: National Children's Oral Health Survey of South Africa (2002): dmft-scores for 6-year-olds per province.

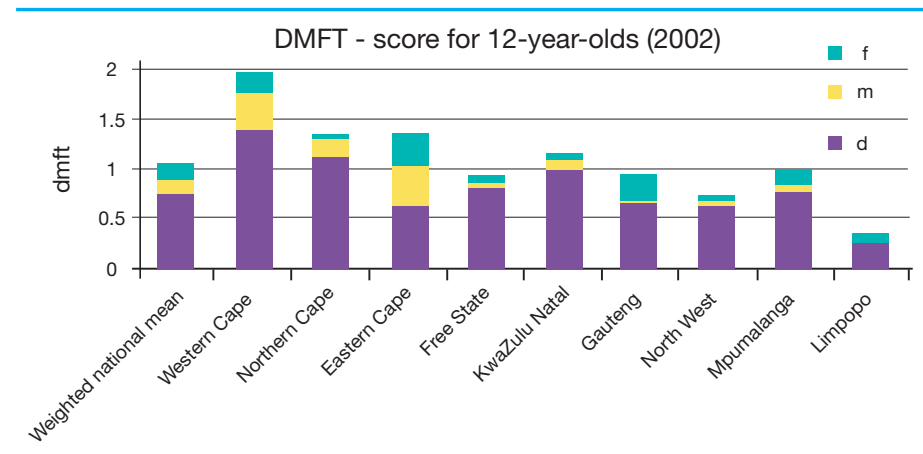

Figure 4: National Children's Oral Health Survey for South Africa (2002): DMFT-scores for 12-year-olds per province.

\section{RESULTS}

Caries experience among 12-year-olds in the Western Cape was 62\% (national mean: 37\%) and the percentage of untreated caries was $52 \%$ (Figure 2), making the province that with the highest caries experience, while Northern Cape and Eastern Cape recorded figures of $47 \%$ and $49 \%$ respectively. Limpopo had the lowest caries experience of $16 \%$. The national percentage for untreated caries in 12-year-olds was $22 \%$ less than the result for the Western Cape (Figure 2).

Severity of dental caries was measured by the dmftscore in primary teeth (Figure 3). The dmft-score for 6 -year-olds in the Western Cape of 5.5 was almost double the national mean of 2.87. Within the Western Cape, the d-component (3.81) contributed to $70 \%$ of the dmft-score, the m-component (1.57) contributed $29 \%$ and the f-component was only $2 \%$ of the dmftscore. Similar cumulative proportions of dmf were found in other provinces except for Gauteng where the f-component contributed $14 \%$.

The DMFT-score for 12-year-olds in the Western Cape of 1.97 was double the national mean of 1 (Figure 4). Within the Western Cape, the D-component (1.39) contributed $70 \%$ of the DMFT-score, the M-component (0.39) contributed $20 \%$ and the F-component (0.19) was $10 \%$ of the total DMFT-score. None of the other provinces had similar cumulative proportions of the different components for DMFT. In Limpopo, the $\mathrm{M}$-component was 0.09. Gauteng had the highest F-component among all provinces with $F=0.34$ accounting for $14 \%$ of the DMFT-score.

Western Cape surveillance data: 2011 - 2015 Caries experience for the province for 6-year-olds was $84 \%$ while untreated caries recorded a level of $74 \%$. This means that three quarters of all 6 yearolds had active caries which was untreated (Figure 5). The Overberg district and the West Coast showed the highest caries experience in the province with 94\% and 92\% respectively. Central Karoo had the lowest caries experience in the province with $77 \%$. Untreated caries remained slightly lower than caries experience for all the districts except for the West Coast where untreated caries was almost as high as caries experience.

Caries experience among 12 year-olds was at $67 \%$ and untreated caries reached $62 \%$ (Figure 6). The Overberg sub-district and the Cape Winelands had shown the highest caries experience in the province with $87 \%$ and $78 \%$ respectively. Central Karoo had the lowest caries experience in the province with $43 \%$. The high levels of caries experience were mostly due to untreated caries.

The dmft-score for 6 year-olds in the Western Cape was 6.2 (Figure 7). In the Cape Winelands and Overberg the numbers of missing teeth were almost half of the numbers of those teeth being affected by caries. In the West Coast district each child had on average one tooth missing and five teeth with active caries. 
The DMFT-score for 12 year-olds was 2.4 with the Overberg district having the highest mean DMFTscore in the province and Central Karoo the lowest (DMFT = 1). The severity of caries among 12-yearolds in the Western Cape was more than double the national mean in 2002 (Figure 8).

When comparing with findings for caries severity among 6 year-olds in the National Survey of 2002 and the current surveillance data, it was found that the mean dmft had increased from 5.5 to 6.2. Student's t test showed that this increase is statistically significant $(p=0.039)$.

Similarly, the caries severity among 12 yearolds in the National Survey of 2002, measured as the mean DMFT, increased from 2.0 to 2.5, a statistically significant change $(p=0.024)$.

\section{DISCUSSION}

The findings from the current surveillance data in the Western Cape related to caries experience, shows that untreated caries and caries severity among age groups 6 - and 12 year-olds, have remained high between 2002 and 2015. The caries experience in the Western Cape for 6-yearolds during the period 2011-2015 was 84\% compared with $82 \%$ in 2002 . Only $16 \%$ of 6 -yearolds in the Western Cape are caries free. This figure is far below the goal of $50 \%$ recommended by the National Department of Health which was proposed for 2000. ${ }^{25}$ Similarly, caries experience in 12 year-olds has increased from 62\% in 2003 to $67 \%$ in 2015.

Untreated caries in 6 year-olds dropped 1\% from $75 \%$ in 2003 to $74 \%$ in 2015 . However in the 12 year-olds, untreated caries increased from $52 \%$ in 2002 to $62 \%$ in 2015. A similar trend was observed between 1988 and 2002 by Van Wyk when the previous two National oral health surveys for South Africa were compared. ${ }^{25}$ This observation emphasizes that the majority of dental caries among young children remains untreated. The finding raises serious concern since untreated dental caries progresses towards complications such as irreversible pulpitis, pulpal necrosis, dental abscess and facial cellulitis, which in some cases can be very severe. ${ }^{26}$ Most of these are associated with excruciating pain, limited jaw opening and reduced quality of life. All of these can be prevented by daily tooth brushing with fluoridated toothpaste, reduced sugar intake and an annual dental examination.

Among 6-year-olds, caries severity increased between 2002 and 2015 by 13\%, from dmft 5.5 to 6.2 , whilst a $20 \%$ increase was recorded amongst 12 year-olds, from DMFT of 2 to 2,5. A positive observation is that caries severity in 12-year-olds in the Western Cape remains below the WHO global goal of less than 3 (by 2000). ${ }^{27}$ However, it is above the RSA national goal of 1.5 as set by the Department of Health. ${ }^{20}$ Similar DMFT-scores of $2.14-2.5$ among the "Coloured" population group were found by Ayo-Yusuf in 2007. ${ }^{28}$
Caries experience for 6-year-olds (2011-2015) ॠ Caries experience $\quad \%$ Un-treated caries

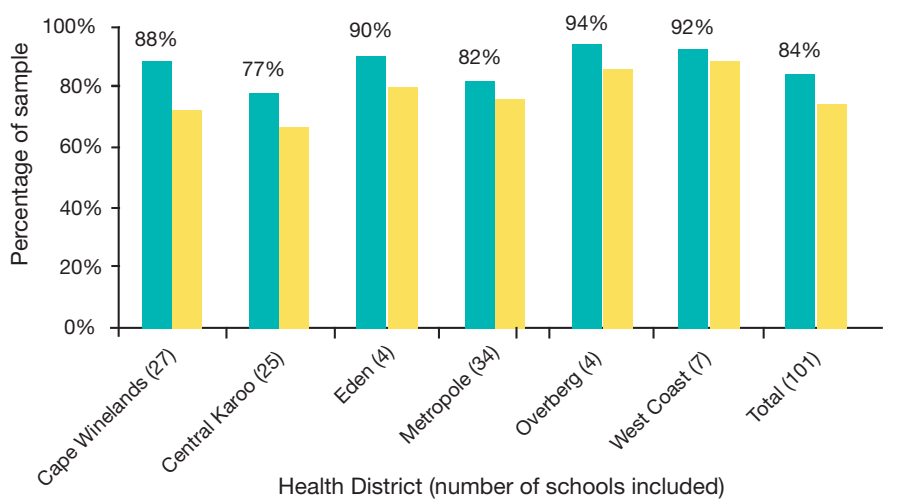

Figure 5: Western Cape Caries Experience by District among 6-year-olds (2011 - 2015)

Caries experience for 12-year-olds (2015)

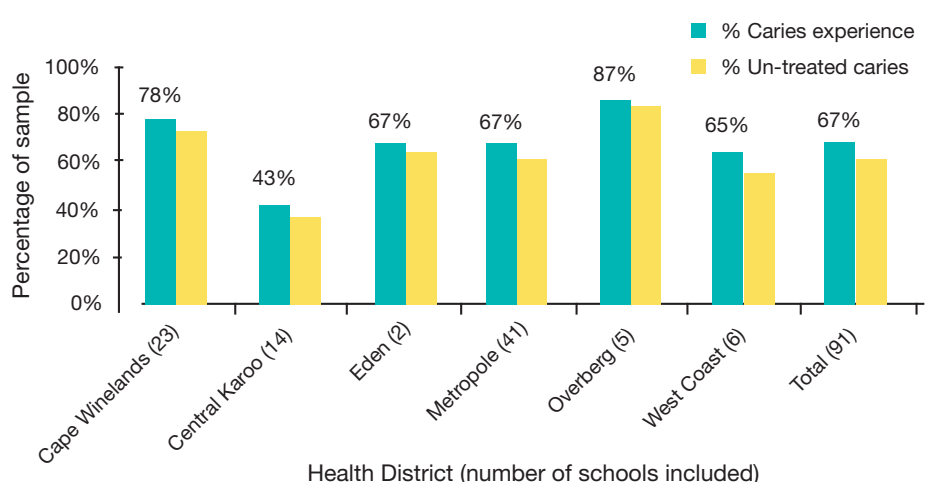

Figure 6: Western Cape Caries Experience by District: 12 Year-olds (2011 - 2015)

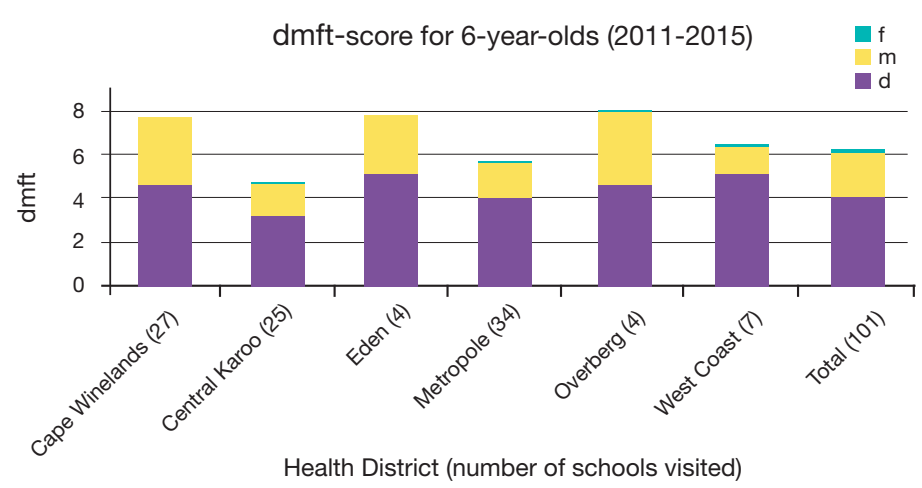

Figure 7: Western Cape Caries Severity by District: 6 Year-olds (dmft) $(2011$ - 2015)

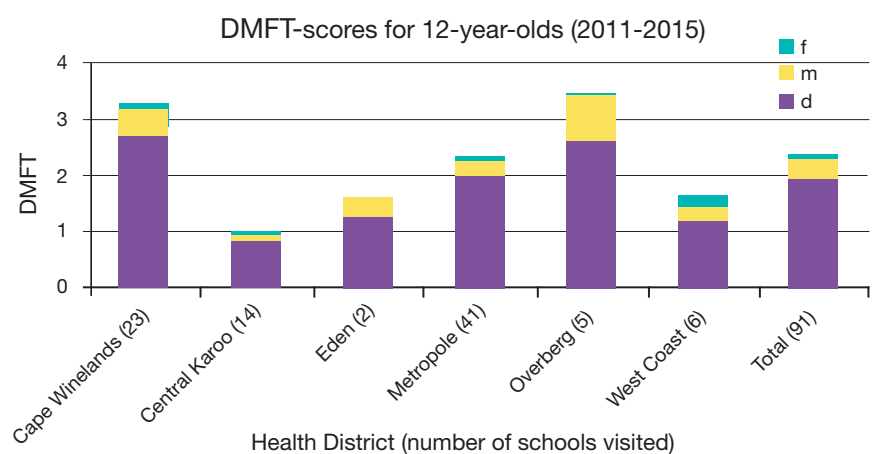

Figure 8: Western Cape Caries Severity by District: 12 Year-olds (DMFT) $(2011-2015)$ 
The increase in caries experience and severity can be explained by the continued consumption of a high sugar diet as well as a limited access to basic oral health care services. ${ }^{22}$ The high rate of urbanization in the Western Cape also might have contributed to the high unmet treatment need, as the number of dental clinics and oral health professionals has not increased at the same rate as population growth. ${ }^{29}$ Good access to basic oral health care is essential in planning future strategies such as the National Development Plan, ${ }^{30}$ Health Care $2030^{31}$ and National Health Insurance. ${ }^{32}$

Poor oral health will contribute to general health problems and it is for this reason that the high prevalence of early childhood caries should be a serious concern to the country. Aspects of life such as growth, cognitive and general development, interferences with sleep, poor appetite, poor school behaviour, eating patterns and negative self-esteem may be affected. ${ }^{33}$ Dental disease in children leads to lost school time due to absenteeism and has been shown to decrease academic performance. ${ }^{7}$ Oral health programmes to promote good oral health in the school setting and at clinics are very limited in the province, ${ }^{22}$ and such programmes that are there, may not be well managed.

\section{CONCLUSION}

Given the persistently high levels of caries among children recorded in the period from 2002 to 2015, the current prevention strategies are clearly failing. Although oral disease does not contribute to high mortality rates, the effect on morbidity is a cogent issue and many people who seek health care in the public sector require urgent dental treatment. The burden of oral disease will worsen over time and will continue to result in more hospital admissions with dental sepsis if the current limited access to basic oral health care is not addressed by health managers. Promoting oral health among children is not solely the responsibility of oral health professionals. Others, such as nurses, home based carers, social workers, community health workers and clinical associates can also be utilized to provide oral health instruction and education to patients. Training of these individuals can be provided by oral health professionals with the ultimate goal of equipping patients to manage self-care.

Oral health care must be regarded as a right that each person can enjoy and therefore it is crucial for decision makers to implement existing health strategies to prevent oral disease and promote good oral health.

\section{RECOMMENDATIONS}

An oral health strategy needs to be implemented that focuses on promoting good oral health and preventing oral disease, notably dental caries. This requires a shift towards a preventive approach instead of a predominantly emergency service of dental extractions. All main public dental clinics (where a dentist is present each day of the week) should at least be able to offer the basic oral health package. The following recommendations are made:

\section{Antenatal clinics and Road to Health booklet}

The general health of children is monitored closely during the first five years though timeous immunizations. At the same time, growth development is charted on the "Road to Health Booklet". The oral health section in the booklet which includes charting for dental caries, should be completed by an oral hygienist, a dental therapist or a dental practitioner. However, due to a serious shortage of oral health professionals in the public sector, the oral health section in the booklet most commonly is simply not completed. Other health workers such as nurses or community health workers should be allowed to complete the section on oral health and the necessary training should be offered to them to perform early dental screening of children.

\section{Promotion of good oral health habits}

Strategies that focus on Mother and Child Care should focus on the oral hygiene of mother and child, infant feeding practices and diet of mother and child. The deleterious effect of adding sugar to a feeding bottle should be emphasized.

Immunization schedule

Exposure to oral health education during different immunization appointments may influence behaviour in order to promote good oral health. Interventions can be initiated at the following time frames:

- Time frame 1: From 9 months to age 18 months

- Time frame 2: From 19 months to age 6 years

The necessary training should be offered to nurses to perform early dental screening of children who are attending immunization clinics.

\section{Training workshops for Early Childhood} Development Centres

A comprehensive crèche training programme should be implemented in both registered and non-registered ECD (Early Childhood Development) facilities in the rural areas as has been done in the Cape Winelands District Municipal area.

\section{Life skills in primary schools}

Closer cooperation with the Department of Basic Education should be encouraged to increase the exposure of oral health education that children receive during their school years. Children can be introduced to good oral habits e.g. daily tooth brushing with fluoridated toothpaste as part of the official Life Skills curriculum.

\section{Supervised daily tooth brushing programmes}

Introduce daily supervised tooth brushing programmes at schools and early childhood centres. The foundation phase (Grade R, 1 and 2 learners) should be targeted. The integrated school health team and the community health workers can assist with supervision and in some cases a community volunteer can also play this role.

Selected pit and fissure sealant programmes The combined effect of tooth brushing and fissure sealant placement is more effective than one regimen alone. Smooth surfaces and fissures of teeth should be protected against decay. Schools that are on the national nutrition programme should be targeted.

The targeted age groups for selective pit and fissure sealant programme are $6-7$ year-olds (grade $R$ and 1) to seal the first permanent molars and $11-12$ year-olds (grade 6 and 7) to seal the second permanent molars. 
Household visits by ward-based health teams Community Health Workers (CHW) also known as Community Based Carers should be offering oral health instructions $(\mathrm{OHI})$ and oral health education $(\mathrm{OHE})$ to parents when households are visited. Concurrent with instructions and education on oral health, CHW's should also disseminate tooth brushes and fluoridated tooth paste meant for the pre-school children of that particular household.

\section{Information management}

Information on dental services in the public sector needs to be investigated to evaluate the quality of oral health programmes and whether these services adhere to national and provincial policy recommendations.

\section{References}

1. Mathabathe NC. Oral health practitioners and HIV/AIDS: Knowledge, attitudes and practices. MSc (Public Health) Research Report, Faculty of Health Sciences, University of the Witwatersrand, Johannesburg, 2006.

2. Peerbhay F, Barrie RB. The burden of early childhood caries in the Western Cape Public Service in relation to dental general anaesthesia: implications for prevention. South African Dental Journal 2012; 67 (1): 14-9.

3. Department of Health. Report: National Children's Oral Health Survey. South Africa; 2003: 1-18.

4. Casamassimo PS. Beyond the dmft: the human and economic cost of early childhood caries. Journal of the American Dental Association 2009; 140(6): 650-7.

5. Naidoo S, Chikte UM, Sheiham A. Prevalence and impact of dental pain in 8-10-year-olds in the Western Cape. Journal of the South African Dental Association 2001; 56: 521-3.

6. Blumenshine SL, Vann WF, Gizlice Z, Lee JY. Children's school performance: Impact of general and oral health. Journal of Public Health Dentistry 2008; 68: 82-7.

7. Jackson SL. Impact of poor oral health on children's school attendance and performance. American Journal of Public Health 2011; 101(10): 1090-6. Available at: http://www. pubmedcentral.nih.gov/articlerender.fcgi?artid=3222359\&tool $=$ pmcentrez\&rendertype $=$ abstract.

8. Van Wyk PJ. Caries status and treatment needs in South Africa: Report of the 1999 - 2002 National Children's Oral Health Survey, South African Dental Journal 2004; 59 (6): 238 -42.

9. World Health Organization (WHO). Oral Health Surveys: Basic Methods - 5th edition, 2013.

10. Majewski RF, Snyder CW, Bernat JE: Dental emergencies presenting to a children's hospital. ASDC J Dent Child 1988; 55: 339-42.

11. BC Ministry of Health. Population Health and Wellness: Evidence review - Dental Public Health. 2006. Available from: $<$ http://www.health.gov.bc.ca/.../publications/.../Model_Core_ Program_Paper_Dental.pdf $\rightarrow$.

12. Elice CE, Fields HW. Failure to thrive: review of the literature, case report and implications for dental treatment. Pediatr Dent 1990; 12: 185-9.

13. Acs G, Lodolini G, Kaminski S, Cisneros GJ. Effect of nursing caries on body weight in a pediatric population. J Pediatr Dent 1992; 14: 302-5.

14. Tsakos G, Watt R. University College London News 2004 Available from: http://www.ucl.ac.uk/news/newsarticles/0315/190315-more-third-children-embarassedsmile-teeth.

15. Marcenes W, Kassebaum NJ, Bernabé E, Flaxman A, Naghavi M, Lopez A. Global burden of oral conditions in 1990-2010: A systematic analysis. Journal of Dental Research 2013; 92(7): 592-7.

16. Clewett JA, Treasure ET. A retrospective study of dental general anaesthesia carried out in children living in North Wales 1995 1998, Community Dental Health 2004; 21: 212 -6.

17. Kakounaki E, Tahmassebi JF, Fayle SA. Further dental treatment needs of children receiving exodontias under general anaesthesia at a teaching hospital in the UK,
International Journal of Paediatric Dentistry 2006; 16: 263-9. 18. Albadri S, Jarad FD, Lee GT, Mackie IC. The frequency of repeat of general anaesthesia for teeth extractions in children, International Journal of Paediatric Dentistry, 2006; 16: 45-8.

19. Government of the Western Cape. National Oral Health Policy 2003, Available from: https://www.westerncape.gov.za/ text/2003/national_policy_oral_health_sa.pdf.

20. Department of Health. South African National Oral Health Strategy 2004; Pretoria, 1 - 31.

21. Department of Health. Norms and Standards for Oral Health in South Africa 2005, Available from: <http://www.doh.gov.za/ docs/policy/strategy.pdf> Accessed on the 4th of October 2012

22. Smit DA. Availability of the basic oral health care package in the Western Cape: SA division of the IADR, CSIR - Pretoria, 3- 4 September 2015.

23. Gussy MG, Waters EG, Walsh O, KilpatrickNM. Early childhood caries: current evidence for aetiology and prevention, Journal of Paediatric Child Health 2006; Jan -Feb; 42 (1 - 2): 37-43.

24. Department of Health. In : van Wyk PJ (ed) National Health Survey, South Africa 1988/89. Pretoria: Government Printer, 1994.

25. Van Wyk C, Van Wyk PJ. Trends in dental caries prevalence, severity and unmet treatment need levels in South Africa between 1983 and 2002. SADJ : Journal of the South African Dental Association 2010; 310: 312-4.

26. Monse, B, Heinrich-Weltzien, R, Benzian, H, Holmgren, C. and Van Palenstein Helderman, W. (2010), PUFA - An index of clinical consequences of untreated dental caries. Community Dentistry and Oral Epidemiology, 38: 77-82. doi:10.1111/ j.1600-0528.2009.00514.x

27. World Health Organization, Oral Health Goals 1983; Available from: http://apps.who.int/iris/bittream/10665/169477/1/25808.pdf

28. Ayo-Yusuf O, Ayo-Yusuf IJ, Van Wyk PJ. Socio-economic inequities in dental caries experience of 12-year-old South Africans: policy implications for prevention. Journal of the South African Dental Association, 2007; 6: 8-11.

29. South African Government. National Health Insurance in South Africa Policy Paper 2011, Available from: <www.gov.za/ sites/www.gov.za/.../nationalhealthinsurance.pd.> Accessed on 24 June 2015.

30. South African Government. National Development Plan 2030, Executive Summary-National Development Plan 2030 - Our future - make it work 2013, Available from: <http://www.gov. za/issues/national-development-plan-2030> Accessed on 24 June 2015

31. Western Cape Government. Healthcare 2030: A Future Health Service for the Western Cape, 9 October 2013 Available from: http://www.westerncape.gov.za/assets/departments/health/ healthcare2030.pdf.

32. Statistics South Africa. Mid-year population estimates 2016, Statistical release P0302, 2016, Available from: https://www. statssa.gov.za/publications/P0302/P03022016.pdf Accessed on 22 May 2017.

33. Locker D. Concepts of Oral Health, Disease and the Quality of Life. in: Slade GD, Editor. Measuring Oral Health and Quality of Life, Chapel Hill: University of North Carolina, Dental Ecology 1997: 11-23.

34. Ayhan $\mathrm{H}$, Suskan E, Yildirim S. The effect of nursing or rampant caries on height, body weight and head circumference. J Clin Pediatr Dent 1996; 20: 209-12. 